\title{
A educação entre os Parintintim: temos muito a aprender com eles
}

Waud H. Kracke ${ }^{1}$

Doutor em Antropologia e professor da Universidade de Illinois em Chicago.

Pesquisador graduado do Chicago Institute for Psychoanalysis.

É membro da Associação Americana de Antropologia e da Associação Brasileira de Antropologia $e$ da Federação Internacional de Educação Psicanalítica.

E-mail: luvillela@aol.com

Como qualquer outro aspecto de uma cultura, o conceito de educação da criança varia muito de uma cultura para outra. Nos países industrializados, e de tradição européia, concebemos a educação em termos de ensino: os pais ensinam as crianças e, depois, mandam-nas à escola, onde são os professores que as ensinam. Muitas vezes, pensa-se nesse tipo especial de comunicação que chamamos de ensino quase como se fosse a transmissão de um fluido: os pais, os professores, os mais velhos ou os mais cultos têm o saber e tentam derramar o saber adulto dentro da cabeça das crianças. Se uma criança é mal-educada, a culpa é dos pais que não a criaram bem.

Os índios Parintintim, com os quais passei bastante tempo, ao longo de cerca de 25 anos, conceitualizam bem diferentemente esse processo comunicativo de aprendizado. Não é tanto uma questão de ensino, mas de como aprender. Pergunto a um sujeito: "Quem ensinou a você esse mito?" ou "Quem lhe ensinou a fazer isso?". Um Parintintim em geral responde: "Não, eu mesmo aprendi. Sentava ao lado do meu pai [ou do meu sogro], escutava ele contar as histórias, e depois eu sabia" ou "Ia caçar com meu pai, via ele caçar, e assim eu aprendi". Para o Parintintim, aprender é uma atividade da criança, uma tarefa ativa, uma conquista da pessoa; não uma recepção passiva de um educador, seja pai, seja professor.

Entendi esse conceito no decorrer de várias visitas aos Parintintim, escutando-os, presenciando e vendo as atividades de muitos indivíduos. Toleraram a minha presença a partir de janeiro de 1967, quando cheguei sem avisar à aldeia de Canavial, na beira do igarapé Ipixuna, afluente do rio Madeira. Apresentei-me a Paulinho e pedi licença para voltar e ficar lá. (A carta que eu havia mandado para as missionárias do Instituto Lingüístico do Verão que trabalhavam em Canavial, para avisá-los da minha chegada, ficara em Porto Velho aguardando a volta delas para a tribo.) Paulinho, com a hospitalidade de um grande chefe Parintintim, me convidou para passar o mês de fevereiro em Canavial; e daí, ao longo de mais 25 anos, voltei muitas vezes para curtir a hospitalidade e paciência de vários chefes Parintintim.

1. Como brasilianista, publicou Force and Persuasion: Leadership among the Parintintim Indians of Brazil (Força e persuasão: liderança entre os índios Parintintim do Brasil), entre outras obras. De passagem pelo Brasil, quis colaborar com a revista Comunicação \& Educação com um relato sobre a educação entre os Parintintim que, formalmente, 
Ao chegar ao Brasil, inteirei-me do importante trabalho antropológico desenvolvido no Museu Nacional do Índio e no Programa de Pós-Graduação da Universidade Federal do Rio de Janeiro, onde pude conhecer diversos antropólogos brasileiros, entre os quais Roque Laraia, que estudou os Tupi, e Aryon Rodrigues, lingüista que se dedica ao estudo da língua Tupi. Devo a Aryon Rodrigues os primeiros rudimentos da língua dos Parintintim e da gramática básica de seu idioma; e a Roque Laraia, a oportunidade de trocar idéias sobre a estrutura social tupi. A minha primeira comunicação sobre o meu trabalho de campo foi apresentada numa aula dele.

Também conheci nomes importantes da Antropologia como Gilberto Velho e Roberto da Matta. Com eles tive os primeiros contatos com a Psicanálise brasileira, além de muitas horas de conversa estimulante sobre o trabalho de campo.

Além disso, ainda pude aproveitar a biblioteca do Museu Nacional para estudar os poucos escritos sobre os Parintintim, sobretudo os artigos de Kurt Nimuendajú, que chefiou a primeira expedição do Serviço de Proteção aos Índios - SPI para entrar em contato com eles em 1922.

Durante essa estada, conheci Nunes Pereira, um dos primeiros pesquisadores a conhecer os Parintintim depois do contato de Nimuendajú. Biólogo autodidata, Nunes Pereira escreveu a primeira monografia sobre o peixe-boi amazônico; mas no decorrer das pesquisas para esse estudo ictiológico, ele encontrou vários grupos indígenas amazônicos e se interessou pela mitologia comparada. Gravou vários mitos parintintins, em tradução para o português; e registrou-os no livro Moronguetá: um Decameron indígena ${ }^{2}$. Ele me contou as aventuras entre os Parintintim e observações que suplementaram aquelas já publicadas por Kurt Nimuendajú.

Nesse período, consegui uma passagem de navio e fui pedir licença ao chefe dos Parintintim, Paulinho, para passar algum tempo com eles em Canavial, estudando sua língua e hábitos. Depois de aceito, voltei para Porto Velho apenas para comprar uma rede e o que mais precisasse para ficar lá. Em fevereiro de 1967, já estava morando com eles às margens do igarapé Ipixuna. Entrei também em contato com outros grupos Parintintim e travei relações com João Messias, o informante de Nunes Pereira, de quem obtive inúmeras outras informações importantes.

Voltei ainda muitas vezes ao campo durante os anos de 1967 e 1968, época de muita importância para mim e para o Brasil, que atravessava difícil momento político, mas, nesse período, todo meu tempo e minha atenção eram para os Parintintim.

É com base nesse trabalho intenso de pesquisa de campo como antropólo-

tem um caráter mais de trabalho etnográfico do que de ensaio teórico, mas que coloca importantes questões sobre a educação entre os povos indígenas brasileiros. (N.E.)

2. PEREIRA, Nunes. Moronguetá: um Decameron indígena. 2. ed. Rio de Janeiro: Civilização Brasileira, INL, 1980. v. 50-50a. (Retratos do Brasil). go e brasilianista que venho contribuir com a revista Comunicação \& Educação, relatando o que aprendi a respeito dos processos de aprendizado entre eles.

\section{O APRENDIZADO DAS ATIVIDADES PRÁTICAS ENTRE OS PARINTINTIM}

Como entre nós, a educação dos Parintintim é muito complexa e implica diferentes aspectos e conteúdos. Há, inicialmente, uma série de ensinamentos práticos a serem transmitidos - os meninos devem aprender a caçar e a utilizar 
o arco e a flecha, enquanto as meninas aprendem a cuidar das crianças e a limpar as ocas. Isso começa a ser ensinado desde cedo, a partir dos cinco anos, quando os meninos fazem suas primeiras experiências flechando pequenos animais como peixes e lagartas. O mais interessante é que o aprendizado se dá principalmente pelo olhar - as crianças ficam observando os adultos e só depois de muito ver é que experimentam fazer. Podemos dizer que no ato de aprender existe essa dialética entre o observar e o fazer. O menino acompanha o pai na pesca e vai observando como ele usa o arco e a flecha, como calcula a posição e o movimento do peixe e como arma o braço. Aprende também a calcular a posição exata do peixe apesar da refração da luz na água, que o faz parecer ocupar uma posição diferente. $\mathrm{O}$ filho tem ainda o privilégio de receber do pai o peixe pescado e de levá-lo para casa. As meninas, da mesma forma, começam muito cedo a carregar as crianças mais novas no colo, a cavar batatas plantadas na beira do terreiro e a colher peixinhos que bóiam no poço de água envenenada com timbó, na mata. Como os meni-

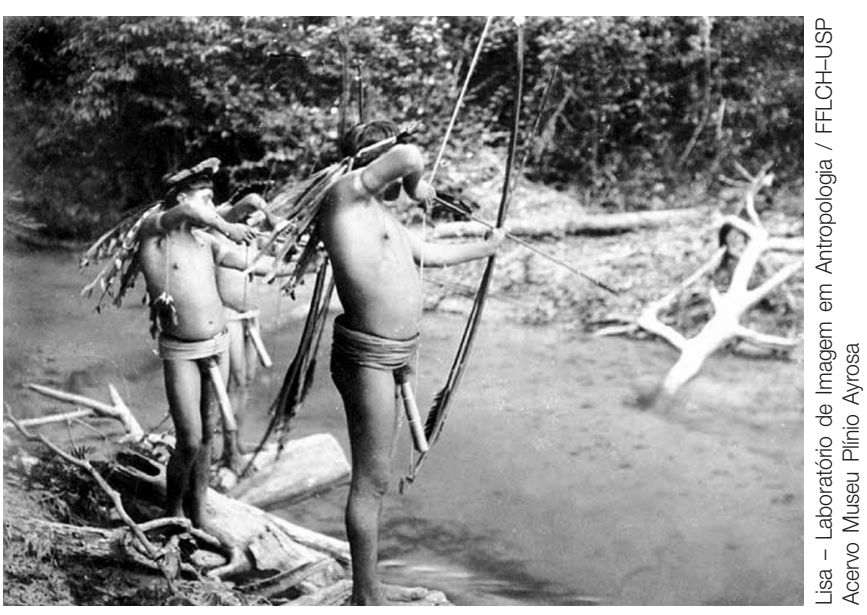

Observar e fazer: método de aprendizado ente os Parintintim. nos, primeiro vêem para depois executar.

Certa vez, procurei ensinar as crianças Parintintim a jogarem frisbee - um disco de plástico que é arremessado a distância para que outro pegue e devolva. Tentei fazer isso pegando suas mãos e fazendo o gesto com elas. Esse método não deu certo. Eles só aprenderam a jogar quando, depois de me observarem jogar várias vezes, o primeiro deles que se sentiu pronto pegou o disco e o lançou de forma corretíssima, mostrando que entendera o gesto com o olhar. Assim, os outros começaram a fazer o mesmo e logo se tornaram peritos em frisbee. Também foi muito interessante perceber que eles desenvolveram uma maneira muito própria de jogar. Enquanto nós, ocidentais, fazemos questão de desenvolver manobras muitos difíceis que façam o disco voar para bem longe, obrigando o outro jogador a correr para pegá-lo, os Parintintim procuravam passar o disco de um para o outro, num círculo não muito grande, contando o número de vezes que o disco permanecia nas mãos deles.

A competição, quando havia, era entre os times de diferentes aldeias e não entre jogadores. $\mathrm{O}$ grupo de uma aldeia vangloriava-se de ter passado $\mathrm{o}$ disco, por exemplo, 55 vezes. Já a outra dizia ter conseguido passá-lo umas 67 vezes. A ênfase era sempre na cooperação. Mais recentemente, os Parintintim aprenderam a jogar futebol e até hoje o apreciam muito. Mas, da mesma forma, as partidas são jogadas de maneira que nenhum time ganhe do outro por muitos gols. Permanece a preocupação com o coletivo, com a cooperação. 
comunicação \& educação • Ano XI • Número 3 • set/dez 2006

Na vida amorosa, o mesmo padrão prevalece. Os meninos e as meninas conversam com os irmãos mais velhos, perguntando detalhes dos encontros com os namorados e as namoradas. Não existe, entre os Parintintim, a idéia de que a criança deva ser protegida do conhecimento da sexualidade. Ao contrário, os adultos falam tão abertamente sobre o assunto na frente das crianças como para qualquer outra pessoa. Além disso, as crianças vêem e se divertem muito quando, escondidas, espiam os casais namorando na praia do igarapé. Mesmo em casa, as redes da família ficam penduradas perto umas das outras, permitindo que crianças percebam o contato entre os pais.

$\mathrm{O}$ olhar e a cooperação são muito importantes para os Parintintim na compreensão da vida. Quem não sabe aprende com quem sabe, seja um adulto, seja um irmão mais velho, seja ainda um estrangeiro como eu.

\section{A COMUNICAÇÃO DOS MITOS E DO SABER HISTÓRICO DE UMA GERAÇÃO PARA A OUTRA}

Além dessas questões, digamos, mais práticas, existe também o aprendizado histórico. Essa é uma parte de grande importância entre os indígenas - é a experiência dos mitos, das histórias e da memória dos antigos. Esse é um tipo de instrução fundamental que coloca as crianças em contato com seus ancestrais. Nesse aprendizado, as crianças não olham, mas escutam. Elas se postam ao lado dos velhos que contam as histórias antigas a respeito do contato com os brancos, das origens de sua tribo e de como chegaram ao território onde moram. As crianças ouvem atentamente e os que já conhecem a história ajudam a narrativa estimulando o contador com perguntas: "E aí, o que ele fez depois?" ou "A quem ele deu o fogo quando o roubou dos inimigos?". Quando a criança se torna mais velha, ela mesma passa a ser uma contadora de mitos.

Esse contato não se dá, como em outros grupos, durante um determinado cerimonial. Infelizmente, quando eu cheguei para viver entre eles, já haviam perdido parte de seus grandes cerimoniais. Assim, essa narração de histórias, através da qual transmitem o conhecimento dos mitos, acontecia muitas vezes durante o trabalho diário, enquanto ralavam mandioca para fazer farinha, por exemplo. Ou então em meio à lavagem da raiz. As histórias são sempre relacionadas às tarefas que estão realizando. Enquanto ralam a mandioca, por exemplo, narram a história de uma velha que comia frutas do mato quando, por acaso, ingeriu um ovo de cobra que cresceu dentro dela. Sempre que a velha chegava perto de um castanheiro, a cobra saía de seu corpo, subia pela árvore e, magicamente, derrubava as castanhas que se abriam no ar. Um dia, os filhos seguem a mulher e ela, sentindo-se envergonhada, pede-lhes que cortem a cobra. Eles obedecem, cortam a cobra e, assim, a velha morre. Seguindo as instruções prévias dela, os filhos queimam seu corpo e saem chorando. Ao retornarem depois de cinco meses, vêem uma roça cheia de mandioca e milho, na qual a velha se transformara.

A maior parte dos mitos que gravei foi contada por homens (talvez por que eu seja um deles). Há mitos que são narrados só por mulheres, e para outras mulheres. Quando voltei ao campo em 1989 com uma assistente, Suzane 
Oakdale, a velha Catarina contou a ela um mito que eu nunca tinha ouvido: a história da Lua. É a seguinte: uma moça namorava um homem que vinha todas as noites encontrá-la, mas de quem ela não via os traços. Para reconhecer o namorado durante o dia, a moça decide esfregar em seu rosto umas sementes de jenipapo. No dia seguinte, procurando pelo moço que tinha as tintas do jenipapo, descobre que o namorado é seu irmão. Sentindo-se culpada, resolve fugir para o céu sob a forma de Lua, enquanto o irmão fica sozinho na terra.

\section{O APRENDIZADO DOS COSTUMES}

Além do aprendizado de atividades práticas do dia-a-dia e da memória ancestral encarnada nos mitos e na história oral, há o aprendizado dos costumes tradicionais. As crianças devem, por exemplo, aprender com quem podem ou não brincar. Depois da infância, quando todas as crianças brincam umas com as outras, elas começam a distinguir os irmãos e os primos cruzados - filhos da irmã do pai que se casou com um homem que pertence à outra metade da tribo (e que entre nós seria chamado simplesmente de primo). Os Parintintim dividem as aldeias em metades, grupos oriundos de diferentes ancestrais e heróis mitológicos que ordenam as relações de parentesco e as interdições amorosas. Para que estas sejam respeitadas, as crianças de certa idade devem aprender as regras de evitação. Precisam evitar os primos cruzados que pertencem à outra metade - procurando não falar e nem mesmo olhar para eles. Uma moça bem comportada aprende rapidamente essas regras e as respeita.

É fácil entender essas interdições: para evitar casamentos endogâmicos, ou seja, entre familiares diretos, as jovens devem se casar com rapazes da outra metade, ou seja, descendentes de outros ancestrais. Ocorre que os filhos desses casamentos acabam sendo parentes próximos dos sobrinhos dessa jovem. São os primos cruzados. Para manter a exogamia, é imprescindível que os primos cruzados se reconheçam e se evitem. Assim se preserva o equilíbrio do grupo. Mitos e lendas ajudam na introjeção desses princípios.

\section{OS PARINTINTIM NA ESCOLA}

Entre os Parintintim não há escola nem qualquer instituição especializada na transmissão dos conhecimentos e mitos. O principal recurso da educação é a participação do aprendiz em quase todas as atividades adultas. A criança, dada a natureza da tribo, acaba presenciando a vida do adulto em quase todas as esferas. Por exemplo, muitas delas me relataram que gostavam de correr pelas matas e pelas praias para olhar os namorados em seus relacionamentos amorosos. E, mesmo nas ocas, durante a noite, dormindo muito próximos uns dos outros, é comum que a criança assista aos adultos mantendo relações sexuais e, como em outras atividades, aprendem observando.

Os adultos, entretanto, procuram impedir que as crianças vejam determinadas partes do corpo. Antigamente os Parintintim usavam pouca roupa - mulheres portavam braceletes e cintos, além da pintura corporal, e os homens, um estojo 


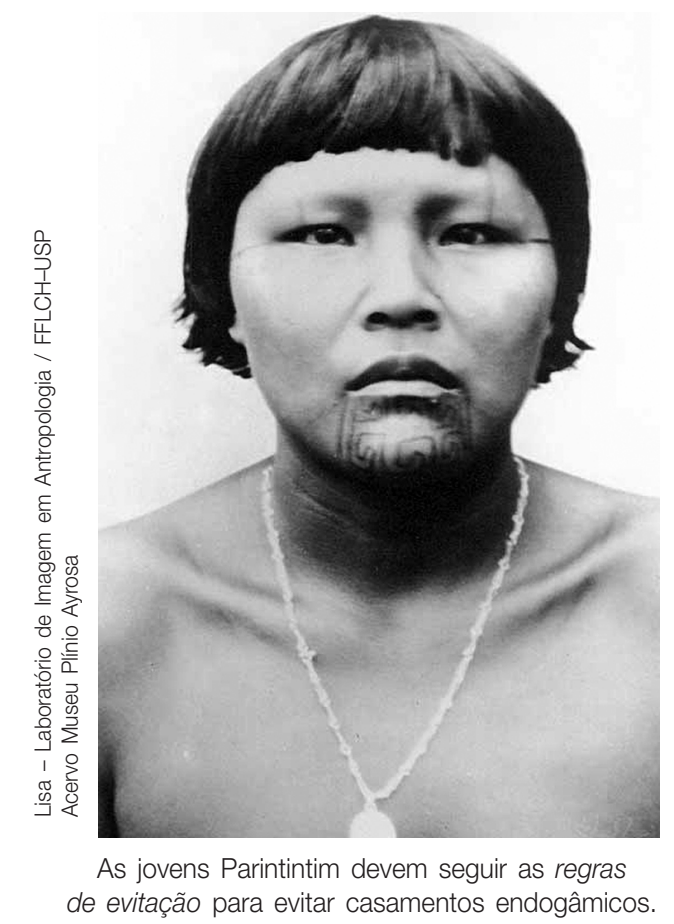

peniano bastante seguro. Ver as partes do corpo do homem é uma grande falta que tem conseqüências graves. Os adultos alertam para os perigos que podem ocorrer às crianças curiosas que ficam espiando os mais velhos durante os banhos.

A vida dos meninos e das meninas é muito separada - cada grupo tem suas obrigações e atividades. Além das divergências de sexo, há diferenças familiares ou de origem que acabam por se refletir na educação, como por exemplo as duas metades nas quais se divide a tribo, cada uma delas com seu simbolismo xamânico. $\mathrm{O}$ individualismo, entretanto, não é estimulado - a educação reforça a igualdade. O princípio geral é de que se deve partilhar tudo, especialmente a comida. Se uma criança ganha uma fruta, deve reparti-la com seu grupo.

Quando cheguei ao Brasil, os Parintintim não tinham nenhum tipo de escola. Os indígenas aprendiam um pouco de alfabetização com as missionárias mencionadas no início deste relato. Posteriormente, a Funai, ao entrar em contato com os índios, criou uma escola para crianças e adultos para que pudessem aprender a ler e a escrever, tanto o português como a língua parintintim. O professor é um índio Parintintim. Acredito que as crianças gostem mais dessa escola da Funai do que das missionárias, cujas aulas assistiam esporadicamente. Elas haviam criado o alfabeto parintintim que funcionava bastante bem, mas o professor que atualmente ensina as crianças introduziu algumas modificações nesse alfabeto, tornando-o bem melhor, mais próximo do sentido dado às palavras pelos indígenas.

Os Parintintim estão passando por uma grande transformação lingüística. Quando cheguei, na década de 1960, havia alguns adultos que falavam mal o português, pois sua língua era o Parintintim. Os mais jovens falavam bem o português, melhor até do que eu. Hoje, entretanto, as gerações mais jovens - de crianças - já não falam mais seu idioma de origem, perderam-no.

Outra mudança é o reconhecimento da escola e do aprendizado como partes diferenciadas ou autônomas da vida. Antes da existência da escola, a educação se misturava ao cotidiano e a todas as atividades dos Parintintim. Até mesmo a educação de uma criança destinada a ser pajé se realiza de forma espontânea. Um dia o pajé, visitado e estimulado pelos espíritos celestes, reconhece através de sonhos a criança que deverá sucedê-lo. Isso acontece quando a criança ainda está no ventre da mãe e se diz que "ela foi sonhada para ser pajé”. A partir de então é preparada para isso, recebendo orientação a fim de desenvolver competências xamânicas. Mas trata-se de uma exceção naquilo que se refere às demais crianças; a educação se dá sem que se precise organizar 
uma instância social especialmente destinada à educação. É a aculturação que está promovendo diferenças nessa forma de encarar o modo de aprender.

\section{OUTRAS PECULIARIDADES DA EDUCAÇÃO INDÍGENA}

Os Parintintim atribuem grande importância às tradições, mas, como os demais povos tupis, estão bem abertos às outras culturas. Por exemplo, trata-se de um dos poucos grupos indígenas que ainda preservam o casamento exogâmico entre as metades da tribo, isto é, cada jovem deve se casar com um homem da outra metade, não descendente de seus ancestrais. Muitos grupos indígenas não respeitam mais essa determinação. Já para outras características sociais, os Parintintim estão prontos à mudança.

O povo indígena tem muitos saberes a transmitir às novas gerações: propriedades medicinais de raízes e folhas de árvores que são reconhecidas e cujo valor eu mesmo pude comprovar; há também um outro conhecimento profundo da natureza, que é a relação entre as espécies vegetais e animais, e está formulado de maneira a estabelecer uma hierarquia entre as espécies, colocando uma como chefe da outra, implicando certa forma de intercâmbio e interdependência entre elas. Estou certo de que nossos cientistas teriam muito a aprender com eles. Grande parte dessa informação científica está contida nos mitos. Por exemplo, a história da velha que vira uma roça de mandioca é na verdade uma metáfora sobre o processo de plantação agrícola - quando, na narrativa, os filhos da velha cortam a cobra, a queimam e a terra germina, estão transmitindo os conhecimentos da agricultura indígena. A narratividade organiza o saber de forma a torná-lo apreensível pelos jovens; é uma organização que prepara o saber para o registro e a transmissão.

O aprendizado é visto de forma cotidiana e natural, de acordo com a reprodução da própria vida. Os Parintintim são adultos pacientes com as crianças e se espantam muito quando vêem os brancos castigarem corporalmente os mais jovens. Para eles isso significa que "os brancos não gostam de seus filhos". Também estranham quando percebem que algumas mães se recusam a dar de mamar aos bebês. Eles chegam a se perguntar se "esses pais não querem que seus filhos sobrevivam". Enxergam até perversidade nesse ato. Mas, por outro lado, sabem punir exemplarmente as crianças e os jovens, assim como as pessoas que não agem de acordo com seus princípios. Assim, aqueles que não repartem os alimentos e não demonstram generosidade são punidos. Que punição é essa? Mostram-se irritados e rejeitam qualquer aproximação até que o infrator corrija seu erro.

A paz da família e da aldeia é um fator de extrema importância para os Parintintim. Assim, quando duas pessoas não conseguem viver sem brigar, uma delas acaba por deixar a aldeia sem que seja necessária a expulsão de qualquer dos envolvidos. Conflitos maiores como a infidelidade entre casais acabam gerando uma tensão muito forte que pode terminar em violência, especialmente quando, nas festas, há consumo de bebidas alcoólicas; porém, de maneira geral a preocupação é com a manutenção da harmonia.

Não há entre os Parintintim uma tecnologia diferente dos demais saberes que eles acumulam em relação à natureza e ao mundo. A tecnologia da pesca 
está integrada à forma como valorizam a própria atividade e como classificam os peixes. Assim, a tecnologia está disponível através dos mesmos meios de acesso pelos quais se obtém conhecimento sobre a vida.

Por tudo que aqui procurei relatar, pode-se perceber que a educação entre os Parintintim é bastante integrada às demais instâncias da vida social e permite a preservação do grupo e a socialização das crianças, reforçando os valores estruturais do grupo.

\section{LIÇÕES DE COMUNICAÇÃO E EDUCAÇÃO}

Como se vê, temos muito a aprender com os indígenas no que tange à comunicação, que tem forte conteúdo integrativo, e à educação, com métodos pedagógicos milenares os quais lhes permitem manter a língua, as tradições e a identidade, por mais que estas estejam permanentemente ameaçadas no convívio com os brancos. A compreensão e a naturalidade com que pensam a educação fazem com que esta seja uma conquista e não uma obrigação, com objetivos menos competitivos e mais integradores que permitem que a relação educativa torne-se mais prazerosa.

E, no tocante à relação entre comunicação e educação, podemos constatar que a forma como se comunicam - com os gestos, as palavras e o olhar - favorece, antes de mais nada, a interação, o contato e a colaboração. Sem uma comunicação harmoniosa, próxima, constante e dialógica, a educação não se realizaria de maneira a conquistar os importantes objetivos a que se propõem os Parintintim.

Resumo: Doutor em Antropologia e professor da Universidade de Illinois em Chicago, Waud $\mathrm{H}$. Kracke colabora com a revista Comunicação \& Educação com um relato sobre a educação entre os Parintintim. De caráter mais etnográfico do que de ensaio teórico, neste trabalho o autor coloca importantes questões sobre a educação entre os povos indígenas brasileiros e o que temos a aprender com eles. Reflete sobre a importância do olhar no aprendizado e sobre os processos de transmissão oral. Os Parintintim não separam ensino prático do teórico e o conteúdo daquilo que aprendem está intimamente relacionado com os valores a partir dos quais se organiza a sua sociedade. Entre eles, a colaboração é mais valorizada do que a competitividade.

Palavras-chave: Parintintim, povos indígenas, mito, narrativa, educação.
Abstract: Waud H. Kracke, PhD in Anthropology and professor at the University of Illinois in Chicago, cooperates with Comunicação \& Educação offering a report on the education among Parintintim indigenous people. In this paper of more ethnographic than theoretical characteristic, the author sets important issues on education among Brazilian indigenous peoples and what we have to learn with them. He reflects on the importance of observation in the learning process and on the oral transmission of knowledge, since Parintintim do not separate the practical from the theoretical teaching. The content of what they learn is closely related to the values from which their society is organized, where collaboration is more valued than competitiveness.

Keywords: Parintintim, Brazilian indigenous peoples, myth, narrative, education. 